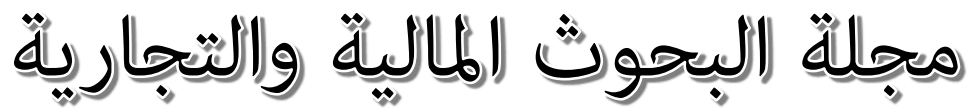

$$
\begin{aligned}
& \text { المجلد (22) - العدد الأول - يناير } 2021
\end{aligned}
$$

\title{
Modelling Financial Risks for Egyptian Insurance Market. Evidence from Insurance Investment Channels
}

\author{
Dr. Mahmoud Elsayed \\ Associate Professor \\ Insurance and Actuarial Sciences department \\ Faculty of Commerce \\ Cairo University
}

رابط المجلة: / https://jsst.journals.ekb.eg/ 


\begin{abstract}
Recently, there has been renewed interest in modelling risks especially in insurance market, there has been substantial research undertaken on the importance of copula in financial risk management field. This study aim to estimate risk measures Value-at-Risk (VaR) and Expected Shortfall (ES) based on the dependence structure between investment channels (Government bonds, Securities available for trade, Securities available for sale and Securities held to maturity) by using elliptical Gaussian copula on data collected from Egyptian insurance market from 2007/2008 to $2018 / 2019$. The principal finding of this research is to measure the financial risk according to the copula estimation. The findings of this paper illustrate that the copula parameter $\rho$ is simmilar to the parameter in the whole market, that is because the life insurance sector has long term conrtacts while the nonlife sector has short term contracts. Moreover, $\mathrm{VaR}$ and $\mathrm{CVaR}$ in all sectors are equevlint that reflects the stability in insurance sector.
\end{abstract}

Keywords: Copula, dependence structure, VaR, ES.

\title{
1. Introduction
}


Recently copulas have been widely used in the area of risk management, finance, insurance and economics. It is useful for modelling multivariate distributions; it also allows combining marginals and decomposing joint distributions into marginals and dependence structure.

The financial risk measure Value at Risk (VaR) shows a figure that expresses the expected losses over a certain period of time based on the desired confidence level assuming normal market conditions. Best (1998) defined the Value at Risk as the maximum amount of money that may be lost on a portfolio over a given period of time, with given level of confidence. The second measure of risk considered in this paper is the Expected shortfall (ES) that is defined as the conditional expectation of loss given that the amount of loss exceeds VaR.

Our paper used several econometric techniques, initially the use of copulas based on the dependence structure between the random variables, and measuring the financial risk measures VaR and ES.

The remainder of this research is constructed as follows. Section 2 is a focus on the literature of the copulas and financial risk measures, section 3 demonstrates details of the suggested models and methodology, section 4 presents the data analysis and evidence results and section 5 conclusions and areas of further research.

\section{Literature Review}

A most useful approach to model a multivariate dependence illustrated by Sklar (1959), based on copula functions. A copula is a joint distribution function of random vectors with uniform margins.

Vine-Copula is flexible to construct a multivariate distribution in case of higher dimensional copula. Aas et al. (2009) developed C-Vine and D-Vine copulas, these approaches construct a tree of bivariate copulas. Dibmann et al. (2013) developed the R-Vine copula which is an upper case of C-Vine and D-Vine copulas that means $\mathrm{C}-\mathrm{Vine}$ and D-Vine copulas are special cases of R-Vine copula. 


\section{Modelling Financial Risks for Egyptian Insurance Market. Evidence from Insurance Investment Channels... Dr. Mahmoud Elsayed}

Kurowicka and Cooke (2005) and Heinen and Valdesogo (2009) assumes the C-autoregressive Vine-Copula and this method aloes still restricted to small number of variables.

Methods of factor copula have been developed by Krupskii and Joe (2013) and Oh and Patton (2013), the main idea of factor copula is it reduces the dimension of the set of data assuming that common factors can represent the dependence structure. Factor copula also considers how the dependence structures behave over time and how to model the dependence structure in different ways, depending on the assumptions of the original variables.

Qu et al. (2009) minimises Kolmogorov-Smirnov distances between the uniform marginals generated from copulas and a univariate random variables for the original distributions.

Genest and Rivest (1993) estimates the bivariate single parameter Archimedean Copula using the method of moments based on Kendall tau.

Berg (2009) or Savu and Trede (2010) applied the pairwise empirical Kendall Tau as a rank dependence measure to estimate the copula parameters for a two dimensions copula. Kojadinovic and Yan (2010) discussed a higher dimensional estimation of copula parameters using Kendall tau.

Jaworski et al. (2010) applied several surveys in finance and insurance in the aspect of copula by modelling the empirical copulas.

Choros et al. (2010) applied parametric and non-parametric estimates of copulas for iid (independent and identically distributed) time series data.

Manner and Reznikova (2012) illustrated different models of copula functions with dependence structures at different points of time and compare the results and the applicability of these copulas in different situations.

Christoffersen et al. (2012) applied the Generalized Hyperbolic Skewed t Copulas (GHST), they considered all marginal distributions to have the same parameters, differs from their original model.

Patton (2009a), Patton (2012a) and Patton (2012b) illustrates the estimation and inference methods of different copulas this study is considered as a 
comprehensive review of copulas in financial risk management and economics.

Embrechts and Hofert (2016) and Alexander (2008) and Andersen et al. (2013) used several mathematical methods and the algorithms of copula to provide a guidance to use copula functions in risk management.

Christoffersen et al. (2012) applied the dynamic copula using the dependence structure for four financial channels and conclude that significant economic values are obtained when dynamic copulas are used. They show how the role of management in the area of finance addresses the relation between the dependence structures of the financial factors, they also mentioned the importance of the copula modelling and the extreme dependencies. Furthermore, they used dynamic asymmetric copula functions for nonGaussian multivariate and conclude that diversifying benefits diminished for developed markets, where emerging markets may diversify benefits.

Elkamhi and Stefanova (2015) demonstrate that based on copulas it allows for increased and asymmetric dependence between extreme asset returns and can yield significant economic values.

Chabi-Yo (2012) illustrated how strong lower tail dependence generates high negative skewness, also showed the increase in Beta factor with respect to lower tail dependence.

Lambert (2007) illustrated the idea of splines for approximating certain ratios that involves the generators of Archimedean copulas. Brahimi and Necir (2012) also used the minimum distance approach between distributions and splines for estimation.

Stephenson (2009) described the extreme value distribution to estimate Gumbel copula parameters in a Bayesian setup. Genest et al. (2011) or Charpentier et al. (2007) applied the non-parametric estimation approach.

Chao Xu and Huigeng Chen (2012) discussed the estimation of the financial measure VaR for a portfolio based on the multivariate VaR models. They used Multivariate EWMA and DCC-GARCH model and the multivariate copulas. 


\section{Modelling Financial Risks for Egyptian Insurance Market. Evidence from Insurance Investment Channels... Dr. Mahmoud Elsayed}

Christian and Hans (2008) applied an autoregressive process to model a dynamic copula in order to estimate the dependence coefficients; they also examined the estimated parameters using goodness of fit tests.

Chen et al. (2009) estimated copula parameters using the maximum likelihood estimation (MLE), they also considered Markov models as a model to estimate the copula parameters as a semi-parametric approach.

Jean et al. (2015) illustrated new tools of copula goodness of fit tests based on non-parametric models. They applied a particular for the simulated data and showed that these tests are more powerful than Kolmogorov-Smirnov, Cramer-von Mises tests.

Peter (2013) used a new class of dynamic copula to characterize dependence structure and asymmetry in big size firms, also documented the differences between dependence dynamics for equity returns and credit spreads. $\mathrm{He}$ concluded that copula parameter (i.e. correlation parameter) increase significantly in case of financial crisis.

Kjersti (2016) introduced the pair-copula constructions (PCCs) in risk management, this model is considered as a flexible of generating a high dimensional copula.

Emmanouil and Nikos (2018) in this paper the authors proposed a new approach of estimating $\mathrm{VaR}$ and $\mathrm{CVaR}$ based on copula. They extended this definition to estimate conditional expected shortfall (CoES). Moreover, they examined the existence of market factors (i.e. size, leverage and Beta) based on systematic risk.

\section{Models and Methodology}

\subsection{Definition of copula}

A Copula is a multi-dimensional function consists of Uniform $[0,1]$ marginals. And satisfy the following conditions:

1. $C:[0,1]^{n} \rightarrow[0,1]$;

2. $C$ is a grounded and n-increasing function; 
3. $C$ has margins $C_{i}$ that satisfy $C_{i}(u)=C(1, \ldots, 1, u, 1, \ldots, 1)=u, u \in[0,1]$

For a univariate CDFs $F_{1}, \ldots, F_{n}, C\left[F_{1}\left(x_{1}\right), \ldots, F_{n}\left(x_{n}\right)\right]$ represents a multivariate copula with marginals $F_{1}, \ldots, F_{n}$.

\subsection{Sklar's Theorem}

If $F(\cdot)$ is an n-dimensional Cumulative distribution function (CDF) with continuous marginals $F_{1}, \ldots, F_{n}$, can be expressed as the following unique copula representation:

$$
F\left(x_{1}, \ldots, x_{n}\right)=C\left(F_{1}\left(x_{1}\right), \ldots, F_{n}\left(x_{n}\right)\right)
$$

Sklar (1959), defined the copula as we can divide a multi-dimensional distribution into univariate marginals and dependence structure as follows;

$$
\begin{gathered}
f\left(x_{1}, \ldots, x_{n}\right)=\frac{\partial F\left(x_{1}, \ldots, x_{n}\right)}{\partial x_{1} \ldots \partial x_{n}}=\frac{\partial C\left(F_{1}\left(x_{1}\right), \ldots, F_{n}\left(x_{n}\right)\right)}{\partial x_{1} \ldots \partial x_{n}}=\frac{\partial C\left(u_{1}, \ldots, u_{n}\right)}{\partial u_{1} \ldots \partial u_{n}} \times \prod_{i} \frac{\partial F_{i}\left(x_{i}\right)}{\partial x_{i}} \\
=c\left(u_{1}, \ldots, u_{n}\right) \times \prod_{i} f_{i}\left(x_{i}\right)=c(\tilde{u}) \times \prod_{i} f_{i}\left(x_{i}\right)
\end{gathered}
$$

where $f\left(x_{1}, \ldots ., x_{n}\right)$ is the density function of $F(\cdot)$

$$
\begin{aligned}
u_{i}= & F_{i}\left(x_{i}\right), i=1, \ldots, n \\
\tilde{u} & =\left(u_{1}, \ldots, u_{2}\right) \\
& c(\tilde{u}) \text { denotes the density function of copula }
\end{aligned}
$$

\subsubsection{Normal Gaussian copula}

Gaussian copula is a multivariate function of normal marginals, assuming $X=\left(X_{1}, X_{2}, \ldots, X_{n}\right)$ is multivariate normal, if and only if:

(a) Its margins $F_{1}, \ldots, F_{n}$ are normally distribution, and

(b) A unique copula function exists, such that

$$
C_{R}^{N}\left(u_{1}, \ldots, u_{n}\right)=\Phi_{R}\left(\phi^{-1}\left(u_{1}\right), \ldots, \phi^{-1}\left(u_{n}\right)\right)
$$




\section{Modelling Financial Risks for Egyptian Insurance Market. Evidence from Insurance Investment Channels... Dr. Mahmoud Elsayed}

Where $\Phi_{R}$ is defined as a multivariate standard normal distribution with correlation matrix $\mathrm{R}$ and the inverse of standard normal marginals $\phi^{-1}$.

\subsubsection{The bivariate normal copula}

The bivariate Gaussian copula is defined as

$$
C\left(u_{1}, u_{2} ; \rho\right)=\int_{-\infty}^{\Phi^{-1}\left(u_{1}\right)} \int_{-\infty}^{\Phi^{-1}\left(u_{2}\right)} \frac{1}{2 \pi \sqrt{1-\rho^{2}}} \exp \left\{-\frac{r^{2}-2 \rho r s+s^{2}}{2\left(1-\rho^{2}\right)}\right\} d r d s,
$$

where $\rho$ is the Pearson coefficient of correlation between marginal distributions and $\Phi^{-1}$ is the inverse of the univariate standard normal function.

\subsection{Risk Measures}

\subsubsection{Value at Risk}

(McNeil et al, 2002) determined that VaR depends on $\alpha$ the confidence level and the time horizon, as:

$$
\operatorname{VaR}_{\alpha}(L)=\inf \{l \in \mathbb{R}: P(L>l) \leq 1-\alpha\}=\inf \left\{l \in \mathbb{R}: F_{L}(l) \geq \alpha\right\}
$$

Assume that $Y$ is a random variable of the returns obtained from the Egyptian insurance market data with a distribution function $F(Y)$. Then $\mathrm{VaR}$ is given by:

$\operatorname{VaR}_{(\alpha)}(Y)=-q^{\alpha}(Y)$

where $q^{\alpha}(Y)$ is the largest $\alpha$-quantile:

$q^{\alpha}(Y)=\inf \{y: P(Y \leq y)>\alpha\}$.

\subsubsection{Expected shortfall}

Expected shortfall measure can be estimated by the conditional expectation using the classical probability theory where ES is defined as:

$E S_{\alpha}=E\left(Y \mid Y<\operatorname{VaR}_{\alpha}\right)$

And, equivalently 
$E S_{\alpha}=\operatorname{VaR}_{\alpha}+E\left(Y-\operatorname{VaR}_{\alpha} \mid Y>\operatorname{VaR}_{\alpha}\right)$.

\section{Models}

For life insurance data, the selected portfolio consists of four dependent investment channels:

$i_{1}=$ Government bonds

$i_{2}=$ Securities available for trade

$i_{3}=$ Securities available for sale

$i_{4}=$ Securities held to maturity

Fitting statistical distributions has been performed using the EASYFIT software, and the results obtained are tested using Kolmogorov-Smirnov, Anderson-Darling test and Chi-Square test, these results show that:

- $i_{1}$ is distributed Generalized Pareto with three parameters $(\mathrm{K}=-1.7181$ $, \sigma=2.0253 \mathrm{E}+7$ and $\mu=-4.5525 \mathrm{E}+5)$

- $i_{2}$ is distributed Generalized Pareto with three parameters $(\mathrm{K}=$ $0.73803, \sigma=8.2228 \mathrm{E}+5$ and $\mu=6.9001 \mathrm{E}+5$ )

- $i_{3}$ is distributed Gamma III with parameters $(\alpha=1.4501, \beta=$ $1.43883 \mathrm{E}+6 \gamma=3.0316 \mathrm{E}+6)$

- $i_{4}$ is distributed Weibull with parameters $(\alpha=1.3278, \beta=3.5402 \mathrm{E}+2$ $\gamma=0)$

For non-life insurance, the selected portfolio consists of four dependent investment channels:

$j_{1}=$ Government bonds

$j_{2}=$ Securities available for trade

$j_{3}=$ Securities available for sale

$j_{4}=$ Securities held to maturity

- $j_{1}$ is distributed LogLogistic with parameters $(\alpha=4.0582, \beta=$ $1.7081 \mathrm{E}+6 \gamma=0$ )

- $j_{2}$ is distributed Weibull with parameters $(\alpha=2.7309, \beta=65670$, $\gamma=0)$ 
- $j_{3}$ is distributed Cauchy with parameters $(\sigma=2.4336 \mathrm{E}+5$ and $\mu=$ $3.2434 \mathrm{E}+6)$

- $j_{4}$ is distributed Frechet with parameters $(\alpha=1.0948, \beta=$ 1.8671E+6).

For insurance market, the selected portfolio consists of four dependent investment channels:

$k_{l}=$ Government bonds

$k_{2}=$ Securities available for trade

$k_{3}=$ Securities available for sale

$k_{4}=$ Securities held to maturity

- $k_{1}$ is distributed Cauchy with parameters $(\sigma=8.4986 \mathrm{E}+5$ and $\mu=$ $1.0870 \mathrm{E}+7)$

- $k_{2}$ is distributed Uniform with parameters $(\alpha=7.5704 \mathrm{E}+5, \quad \beta=$ $1.8368 \mathrm{E}+6$ )

- $k_{3}$ is distributed Weibull with parameters $(\alpha=0.8254, \beta=2.3058 \mathrm{E}+6$ $\gamma=6.3106 \mathrm{E}+6)$

- $k_{4}$ is distributed Frechet with parameters $(\alpha=1.3009, \beta=3.7526 \mathrm{E}+6$ $\gamma=0)$.

\subsection{Data collection, Empirical procedures and results analysis}

The data collected in this paper are for life and non-life Egyptian insurance market from 2007/2008 to 2018/2019 consists of four dependent investment channels: Government bonds, Securities available for trade, Securities available for sale and Securities held to maturity collected from the Financial Regulatory Authority (FRA).

Table (1) amounts invested in securities for life insurance companies. 


\begin{tabular}{|c|c|c|c|c|}
\hline \multirow{2}{*}{ Year } & \multicolumn{4}{|c|}{$\begin{array}{c}\text { LIFE INSURANCE SECUTITES } \\
\text { In Thousands EGP }\end{array}$} \\
\cline { 2 - 5 } & $\begin{array}{c}\text { Government } \\
\text { bonds }\end{array}$ & $\begin{array}{c}\text { Securities } \\
\text { available } \\
\text { for trade }\end{array}$ & $\begin{array}{c}\text { Securities } \\
\text { available for } \\
\text { sale }\end{array}$ & $\begin{array}{c}\text { Securities held } \\
\text { to maturity }\end{array}$ \\
\hline $2007 / 08$ & 1694096 & 818339 & 3374555 & 846990 \\
\hline $2008 / 09$ & 2817975 & 829234 & 3031600 & 1245212 \\
\hline $2009 / 10$ & 2973821 & 1074467 & 3486635 & 1798333 \\
\hline $2010 / 11$ & 3223877 & 1459431 & 4222146 & 1912633 \\
\hline $2011 / 12$ & 6150196 & 1578720 & 4155168 & 1931916 \\
\hline $2012 / 13$ & 7557275 & 1485577 & 4117487 & 1965402 \\
\hline $2013 / 14$ & 8678154 & 1493209 & 5008864 & 1585957 \\
\hline $2014 / 15$ & 9807282 & 1380133 & 4916113 & 2996224 \\
\hline $2015 / 16$ & 10223695 & 1134978 & 5171593 & 4715760 \\
\hline $2016 / 17$ & 9719000 & 905721 & 10254035 & 6236102 \\
\hline $2017 / 18$ & 9896481 & 920933 & 6732350 & 9065620 \\
\hline $2018 / 19$ & 11210420 & 876716 & 6799787 & 9883015 \\
\hline
\end{tabular}

Source: Financial Regulatory Authority (FRA), 2019.

Table (1) shows the amounts invested in a portfolio that consist of four dependent investment channels: Government bonds, Securities available for trade, Securities available for sale and Securities held to maturity for life insurance companies.

Table (2) amounts invested in securities for non-life insurance companies. 


\begin{tabular}{|c|c|c|c|c|}
\hline \multirow{2}{*}{ Year } & \multicolumn{4}{|c}{$\begin{array}{c}\text { NON-LIFE INSURANCE SECUTITES } \\
\text { In Thousands EGP }\end{array}$} \\
\cline { 2 - 5 } & $\begin{array}{c}\text { Government } \\
\text { bonds }\end{array}$ & $\begin{array}{c}\text { Securities } \\
\text { available } \\
\text { for trade }\end{array}$ & $\begin{array}{c}\text { Securities } \\
\text { available for } \\
\text { sale }\end{array}$ & $\begin{array}{c}\text { Securities held } \\
\text { to maturity }\end{array}$ \\
\hline $2007 / 08$ & 1616485 & 968319 & 3187127 & 1329855 \\
\hline $2008 / 09$ & 1667096 & 67054 & 3279040 & 1331627 \\
\hline $2009 / 10$ & 1816538 & 81971 & 3000740 & 1280000 \\
\hline $2010 / 11$ & 3274390 & 87696 & 3496074 & 1251634 \\
\hline $2011 / 12$ & 4506700 & 50245 & 3640024 & 1165056 \\
\hline $2012 / 13$ & 2878587 & 39051 & 3027918 & 2673560 \\
\hline $2013 / 14$ & 1680893 & 47383 & 3463821 & 4576623 \\
\hline $2014 / 15$ & 1620075 & 41398 & 3013076 & 5500245 \\
\hline $2015 / 16$ & 1169295 & 29920 & 2508107 & 6575542 \\
\hline $2016 / 17$ & 1174572 & 41394 & 6805835 & 8460984 \\
\hline $2017 / 18$ & 1316466 & 75928 & 3264195 & 11762778 \\
\hline $2018 / 19$ & 1589727 & 75048 & 4056938 & 13000538 \\
\hline
\end{tabular}

Source: Financial Regulatory Authority (FRA), 2019.

Table (2) shows the amounts invested in a portfolio that consist of four dependent investment channels: Government bonds, Securities available for trade, Securities available for sale and Securities held to maturity for nonlife insurance companies.

Table (3) amounts invested in securities for insurance market. 
مجلة البحوث المالية والتجارية - المجلد (22) - العدد الأول - يناير 2021

\begin{tabular}{|c|c|c|c|c|}
\hline \multirow{2}{*}{ Year } & \multicolumn{4}{|c|}{$\begin{array}{c}\text { INSURANCE MARKET SECUTITES } \\
\text { In Thousands EGP }\end{array}$} \\
\cline { 2 - 5 } & $\begin{array}{c}\text { Government } \\
\text { bonds }\end{array}$ & $\begin{array}{c}\text { Securities } \\
\text { available } \\
\text { for trade }\end{array}$ & $\begin{array}{c}\text { Securities } \\
\text { available for } \\
\text { sale }\end{array}$ & $\begin{array}{c}\text { Securities held } \\
\text { to maturity }\end{array}$ \\
\hline $2007 / 08$ & 3310581 & 1786658 & 6561682 & 2176845 \\
\hline $2008 / 09$ & 4485071 & 896288 & 6310640 & 2576839 \\
\hline $2009 / 10$ & 4790359 & 1156438 & 6487375 & 3078333 \\
\hline $2010 / 11$ & 6498267 & 1547127 & 7718220 & 3164267 \\
\hline $2011 / 12$ & 10656896 & 1628965 & 7795192 & 3096972 \\
\hline $2012 / 13$ & 10435862 & 1524628 & 7145405 & 4638962 \\
\hline $2013 / 14$ & 10359047 & 1540592 & 8472685 & 6162580 \\
\hline $2014 / 15$ & 11427357 & 1421531 & 7929189 & 8496469 \\
\hline $2015 / 16$ & 11392990 & 1164898 & 7679700 & 11291302 \\
\hline $2016 / 17$ & 10893572 & 947115 & 17059870 & 14697086 \\
\hline $2017 / 18$ & 11212947 & 996861 & 9996545 & 20828398 \\
\hline $2018 / 19$ & 12800147 & 951764 & 10856725 & 22883553 \\
\hline Source Finy & & & & \\
\hline
\end{tabular}

Source: Financial Regulatory Authority (FRA), 2019.

Table (3) shows the amounts invested in a portfolio that consist of four dependent investment channels: Government bonds, Securities available for trade, Securities available for sale and Securities held to maturity for insurance market.

Table (4) Descriptive statistics for life insurance companies 


\section{Modelling Financial Risks for Egyptian Insurance Market. Evidence from Insurance Investment Channels... Dr. Mahmoud Elsayed}

In Thousands EGP

\begin{tabular}{|c|c|c|c|c|c|c|}
\hline Sector & Variables & Mean & $\begin{array}{c}\text { Standard } \\
\text { deviation }\end{array}$ & Skewness & Kurtosis & SE \\
\hline \multirow{4}{*}{ Life } & $i_{1}$ & $\begin{array}{c}699602 \\
3\end{array}$ & 3460730 & -0.32 & -1.73 & 999027 \\
\cline { 2 - 7 } & $i_{2}$ & $\begin{array}{c}116312 \\
2\end{array}$ & 296417 & 0.14 & -1.88 & 85568 \\
\cline { 2 - 7 } & $i_{3}$ & $\begin{array}{c}510586 \\
1\end{array}$ & 2014759 & 1.27 & 0.82 & 581611 \\
\cline { 2 - 7 } & $i_{4}$ & $\begin{array}{c}368193 \\
0\end{array}$ & 311237 & 0.95 & -0.76 & 898464 \\
\hline
\end{tabular}

Table (4) illustrates the statistical characteristics of four variables for life insurance companies, showing that Government bonds is negatively skewed while, Securities available for trade, Securities held to maturity and Securities available for sale are skewed to the right, also it is obvious that all variables are platykurtic.

Table (5) Correlation matrix for life insurance data

\begin{tabular}{|c|c|c|c|c|}
\hline Variable & $i_{1}$ & $i_{2}$ & $i_{3}$ & $i_{4}$ \\
\hline$i_{1}$ & 1 & 0.06695 & 0.6953 & 0.7306 \\
\hline$i_{2}$ & & 1 & -0.2773 & -0.4389 \\
\hline$i_{3}$ & & & 1 & 0.7357 \\
\hline$i_{4}$ & & & & 1 \\
\hline
\end{tabular}

Figure (1) Correlation matrix for life insurance

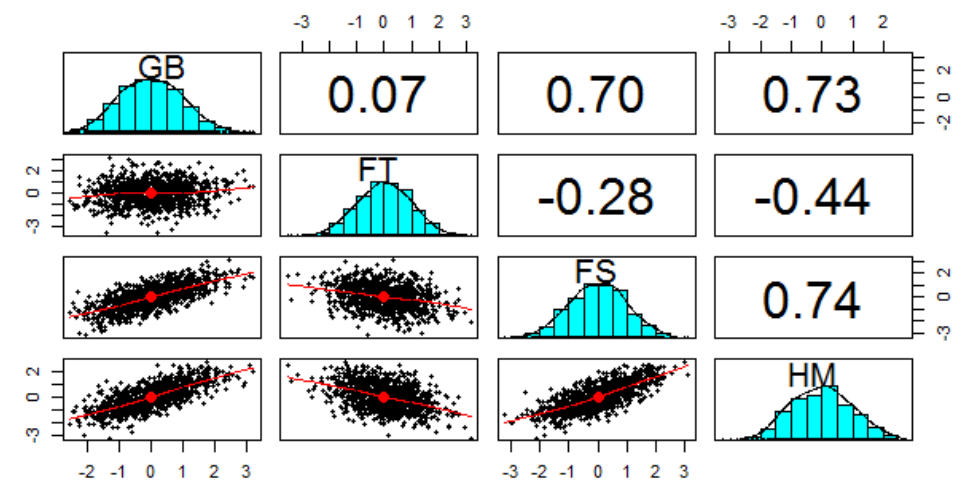


The correlation matrix demonstrated in table (5) and figure (1), presents Pearson correlation coefficient $\rho$ between each pair of investment instruments for life insurance companies (i.e. $\rho_{i 1, i 2}=0.06695$ means that the correlation coefficient between Government bonds and Securities available for trade is positive and weak).

Table (6) Descriptive statistics non-for life insurance In Thousands EGP

\begin{tabular}{|c|c|c|c|c|c|c|}
\hline Sector & Variables & Mean & $\begin{array}{c}\text { Standard } \\
\text { deviation }\end{array}$ & Skewness & Kurtosis & SE \\
\hline \multirow{3}{*}{$\begin{array}{c}\text { Non- } \\
\text { life }\end{array}$} & $j_{1}$ & 2025902 & 1009778 & 1.29 & 0.39 & 291498 \\
\cline { 2 - 7 } & $j_{2}$ & 133784 & 263505 & 2.62 & 5.39 & 76067 \\
\cline { 2 - 7 } & $j_{3}$ & 3561908 & 1091665 & 2.08 & 3.59 & 315136 \\
\hline
\end{tabular}

Table (6) demonstrates the four moments for variables of non-life insurance companies, showing that Government bonds, Securities available for trade, Securities available for sale and Securities held to maturity are positively skewed. Moreover, Government bonds and Securities held to maturity are platykurtic, while, Securities available for sale and securities available for trade are leptokurtic.

Table (7) Correlation matrix for non-life insurance data

\begin{tabular}{|c|c|c|c|c|}
\hline Variable & $j_{1}$ & $j_{2}$ & $j_{3}$ & $j_{4}$ \\
\hline$j_{1}$ & 1 & -0.1199 & -0.1302 & -0.5332 \\
\hline$j_{2}$ & & 1 & -0.1140 & -0.2646 \\
\hline$j_{3}$ & & & 1 & 0.3319 \\
\hline$j_{4}$ & & & & 1 \\
\hline
\end{tabular}




\section{Modelling Financial Risks for Egyptian Insurance Market. Evidence from Insurance Investment Channels... Dr. Mahmoud Elsayed}

Figure (2) Correlation matrix for non-life insurance

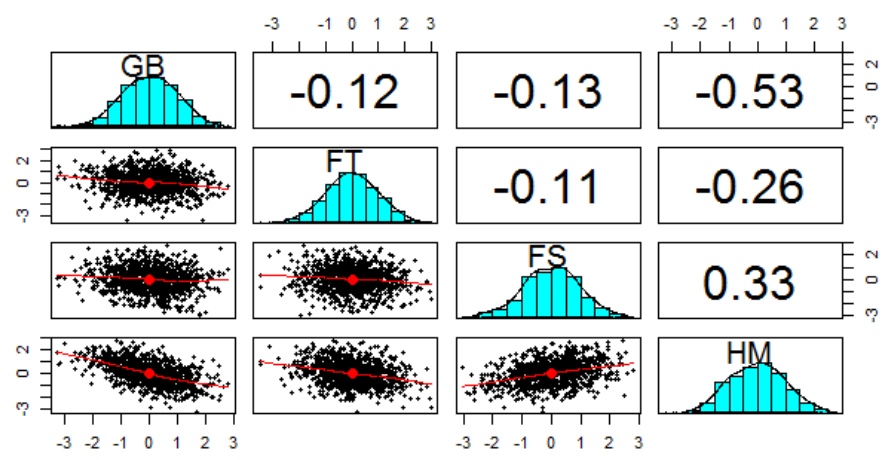

The correlation matrix illustrated in table (7) and figure (2), shows the correlation coefficient $\rho$ between each pair of investment channels for nonlife insurance companies (i.e. $\rho_{j 1, j 2}=-0.1199$ means that the correlation coefficient between Government bonds and Securities available for trade is negative and very weak).

Table (8) Descriptive statistics insurance market In Thousands EGP

\begin{tabular}{|c|c|l|l|l|l|l|}
\hline Sector & Variables & Mean & $\begin{array}{l}\text { Standard } \\
\text { deviation }\end{array}$ & Skewness & Kurtosis & SE \\
\hline & $k_{1}$ & $\begin{array}{l}902192 \\
5\end{array}$ & 3274202 & -0.63 & -1.43 & 945181 \\
\cline { 2 - 7 } & $k_{2}$ & $\begin{array}{l}129690 \\
5\end{array}$ & 311690 & 0.05 & -1.73 & 89977 \\
\cline { 2 - 7 } $\begin{array}{c}\text { Insurance } \\
\text { Market }\end{array}$ & $k_{3}$ & $\begin{array}{l}866776 \\
9\end{array}$ & 2973684 & 1.79 & 2.40 & 858429 \\
\cline { 2 - 7 } & $k_{4}$ & $\begin{array}{l}859096 \\
7\end{array}$ & 7307944 & 0.84 & -0.91 & 2109622 \\
\hline
\end{tabular}

Table (8) demonstrates the four moments for variables of insurance market, showing that Government bonds negatively skewed, while, Securities available for trade, Securities available for sale and Securities held to maturity are positively skewed. Moreover, all securities are platykurtic. 
Table (9) Correlation matrix for non-life insurance data

\begin{tabular}{|c|c|c|c|c|}
\hline Variable & $j_{1}$ & $j_{2}$ & $j_{3}$ & $j_{4}$ \\
\hline$j_{1}$ & 1 & -0.2187 & 0.4974 & 0.6897 \\
\hline$j_{2}$ & & 1 & -0.4663 & -0.6282 \\
\hline$j_{3}$ & & & 1 & 0.6373 \\
\hline$j_{4}$ & & & & 1 \\
\hline
\end{tabular}

Figure (3) Correlation matrix for non-life insurance

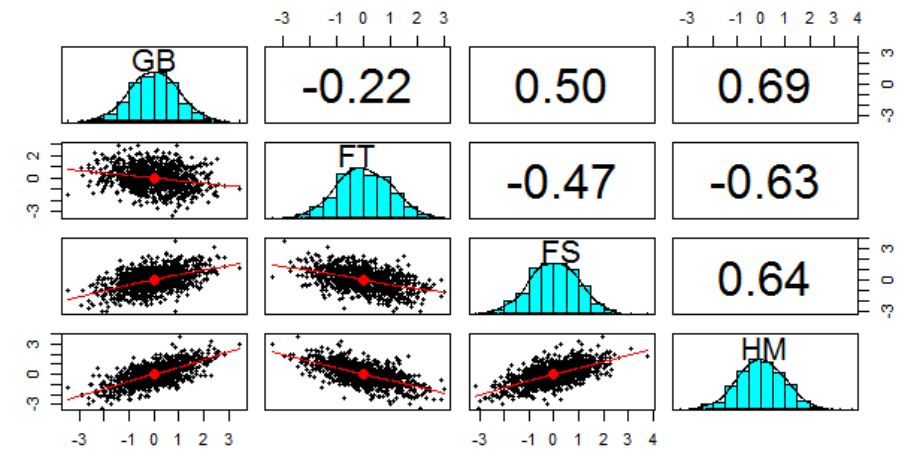

The correlation matrix illustrated in table (9) and figure (3), shows the correlation coefficient $\boldsymbol{\rho}$ between each pair of investment channels for nonlife insurance companies (i.e. $\rho_{k 1 k 2}=-0.2187$ means that the correlation coefficient between Government bonds and Securities available for trade is negative and very weak).

\subsection{Modelling Copula}

The main purpose of copula models is to separate the joint distribution into two parts: marginals and dependence structure.

If a random variable $\mathrm{Y}$ has a distribution function $f$, then the cumulative distribution $\mathrm{F}(\mathrm{Y})$ is uniform within the interval $[0,1]$. 


\section{Modelling Financial Risks for Egyptian Insurance Market. Evidence from Insurance Investment Channels... Dr. Mahmoud Elsayed}

The following steps are required in order to use copula:

1. Estimating the copula parameter(s) (i.e. $\rho$ in case of Gaussian copula)

2. Generating the suitable copula that fits the data.

3. Using the invers functions or the inversion method to generate scenarios from the original marginals to apply the chosen copula.

For simulation we need to perform the following steps:

1. Estimate the correlation matrix from the original marginals, assuming normality using the C.D.Fs F (.) and the inverse of the standard normal C.D.F $\Phi^{-1}($.$) .$

2. Simulating the data to fit a copula from transformed variables that satisfy the copula parameter $\rho$. Then use the invers of these variables $\Phi^{-1}($.$) to$ produce the copula.

3. the former step generates dependent uniform marginals $u_{i}$ to fit a copula, these marginals $u_{i}$ can be simulated to estimate the copula parameter $\rho$ by using the formula $\varepsilon_{i}=F_{i}^{-1}\left(u_{i}\right)$.

Figure (4) the probabilty densty function (pdf) of the gaussian copula generated from life insurance companies investment channels.

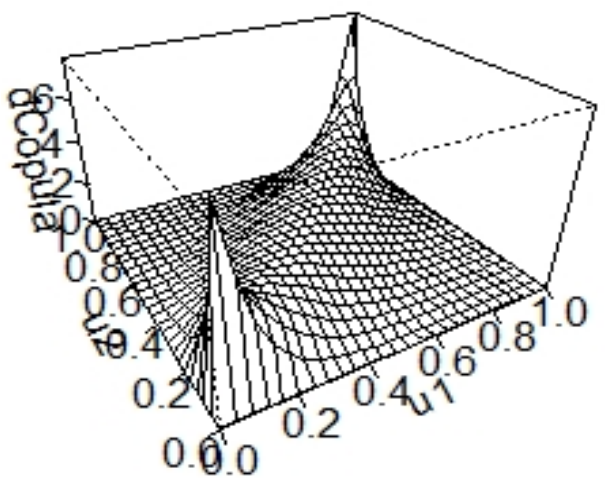

Figure (4) shows the probability densty function for the gaussian copula with estimated parameter $\rho=0.8876$. 


\section{مجلة البحوث المالية والتجارية - المجلد (22) - العدد الأول - يناير 2021}

$\mathrm{VaR}_{1 \%}$ for life insurance companies is 0.01016

$\mathrm{CVaR}_{1 \%}$ for life insurance companies is 0.005422

Figure (5) the probabilty densty function (pdf) of the gaussian copula generated from non-life insurance companies investment channels.

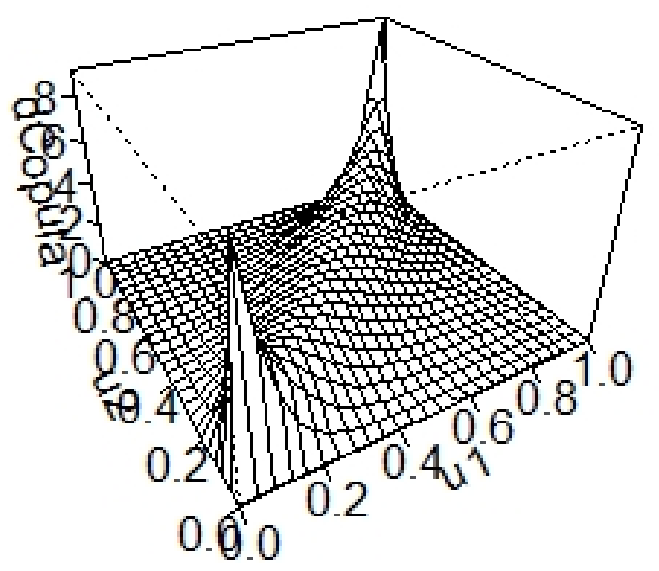

Figure (5) shows the probability densty function for the gaussian copula with estimated parameter $\rho=0.2051$.

$\mathrm{VaR}_{1 \%}$ for nonlife insurance companies is 0.01045

$\mathrm{CVaR}_{1 \%}$ for nonlife insurance companies is 0.004836

Figure (6) the probabilty densty function (pdf) of the gaussian copula generated from insurance market investment channels.

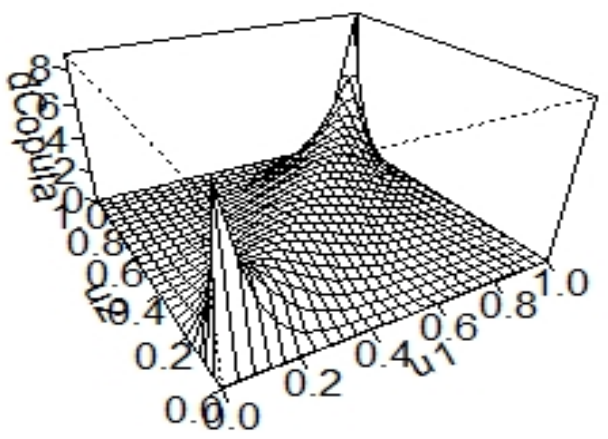

Figure (6) shows the probability densty function for the gaussian copula with estimated parameter $\rho=0.8805$. 


\section{Modelling Financial Risks for Egyptian Insurance Market. Evidence from Insurance Investment Channels... Dr. Mahmoud Elsayed}

$\mathrm{VaR}_{1 \%}$ for nonlife insurance companies is 0.01232

$\mathrm{CVaR}_{1 \%}$ for nonlife insurance companies is 0.004977

\section{Conclusion and Further Research}

This study seeks to measure risks using $\mathrm{VaR}$ and ES for investments instruments for life and non-life Egyptian insurance companies based on Gaussian copula and the dependence structure between variables. We used Gaussian copula to fit a model of a multivariate financial data and use the fitted models to simulate data in order to estimate the risk measures. This paper found out that both life and non-life have an approximately the same risk measure according to the copula estimation because both fit a Gaussian copula with a close dependence measure $\rho$. Further research may consider the use of other types of copula such as t-copula and Archimedean copulas to measure risks, also the extreme value theory may be a useful tool for measuring the tail of the statistical distributions. This paper recommends the use of copula and risk measure to be used in insurance investment funds and stock market.

Table (10) Summary of results for life, nonlife and market VaR and CVaR

\begin{tabular}{|l|c|c|c|}
\hline & $\boldsymbol{\rho}$ & $\mathbf{V a R}_{\mathbf{1} \%}$ & $\mathbf{C V a R}_{\mathbf{1}} \%$ \\
\hline Life insurance co. & 0.8876 & 0.01016 & 0.005422 \\
\hline $\begin{array}{l}\text { Nonlife Insurance } \\
\text { co. }\end{array}$ & 0.2051 & 0.01045 & 0.004836 \\
\hline Market & 0.8805 & 0.01232 & 0.004977 \\
\hline
\end{tabular}

Table (10) describes the summary of results of $\mathrm{VaR}$ and $\mathrm{CVaR}$ for insurance sectors in Egypt, we can conclude that life insurance sector has the copula parameter $\boldsymbol{\rho}$ is simmilar to the parameter in the whole market, that is because the life insurance sector has long term conrtacts while the nonlife sector has short term contracts. Moreover, $\mathrm{VaR}$ and $\mathrm{CVaR}$ in all sectors are equevlint that reflects the stability in insurance sector. 


\section{References}

1. Aas, C. Czado, A. Frigessi, H. Bakken, (2009). Pair-copula constructions of multiple dependence, Insurance Math. Econom. 44: 182-198.

2. Alexander, (2008). Market Risk Analysis, Volume III, Wiley, London.

3. Andersen, TG, Bollerslev, T, Christoffersen, PF, and Diebold, Fx (2013), Financial risk measurement for financial risk management, Handbook of the Economics of Finance, ed. by G Constantinides, M Harris, and R Stulz, vol. 2, Amsterdam: Elsevier Science B. V., 11271220.

4. Best Philip, Implementing Value at Risk, John Wiley and Sons, 1998.

5. Berg, J.-F. Quessy, (2009). Local power analyses of goodness-of-fit tests for copulas, Scandinavian J. Statist. 36: 389-412.

6. Brahim,B.,A. Necir,(2012)," A semiparametric estimation of copula models based on the method of moments", Statistical Methodology,volume 9, issue 4,PP:467-477.

7. Chabi-Yo, F., 2012. Pricing kernels with stochastic skewness and volatility risk. Management Science 58, 624-640.

8. Chao,XU.,and H. Chen (2012)," Measuring Portfolio Value at Risk", LUND University Libraries.

9. Charpentier MJE, Peignot P, Hossaert-McKey M, Wickings EJ. 2007. Kin discrimination in juvenile mandrills, Mandrillus sphinx. Animal Behaviour 73:37-45.

10. Chen, W.B. Wu, Y. Yi, (2009). Efficient estimation of copula-based semiparametric Markov models, Ann. Statist. 37: 4214-4253.

11.Choros, R. Ibragimov, E. Permiakova, (2010). Copula estimation, in: Workshop on Copula Theory and its Applications, Springer, Berlin.

12.Christian M. Hafner,Hans Manner,Dynamic stochastic copula models: Estimation, inference and applications November 28, 2008. 


\section{Modelling Financial Risks for Egyptian Insurance Market. Evidence from Insurance Investment Channels... Dr. Mahmoud Elsayed}

13.Christoffersen, P., Errunza, V., Jacobs, K., and Langlois, H. Is the Potential for International Diversification Disappearing? A Dynamic Copula Approach. Review of Financial Studies, 25(12):3711-3751, 2012.

14.Dißmann, J., Brechmann, E.C., Czado, C., Kurowicka, D.: Selecting and estimating regular vine copulae and application to financial returns. Computational Statistics \& Data Analysis 59, 52-69 (2013).

15.Elkamhi, R., Stefanova, D., 2015. Dynamic Hedging and Extreme Asset Co-movements. Review of Financial Studies 28, 743-790.

16.Emmanouil, N .,K. Nikos(2018)Measuring systemic risk in the European banking sector: a copula $\mathrm{CoVaR}$ approach ,European Journal of Finance, 24(1):1-38.

17.Embrechts, P., Hofert, M. and Wang. R. (2016), Bernoulli and TailDependence Compatibility, The Annals of Applied Probability, 26(3), $1636-1658$.

18.Genest, L.-P. Rivest, (1993). Statistical inference procedures for bivariate Archimedean copulas, J. Amer. Statist. Assoc. 88: 10341043.

19.Genest, J. Nešlehová, N. Ben Ghorbal, (2011). Estimators based on Kendall's tau in multivariate copula models, Aust. N. Z. J. Stat. 53: $157-177$.

20.Heinen, A., Valdesogo, A.: Asymmetric CAPM dependence for large dimensions: The Canonical Vine Autoregressive Model. CORE discussion papers 2009069, Universit'e catholique de Louvain, Center for Operations Research and Econometrics (CORE) (2009).

21.Jaworski, P., F. Durante, , W.K.H“ardle, , \& T.Rychlik, (2010)," Copula Theory and Its Applications", Lecture notes in statistics ; 198 : Proceedings. Springer.

22.Jean-David F., D. Radulović, and M. Wegkamp,(2015)," Asymptotic total variation tests for copulas", Bernoulli 21, no. 3, 1911--1945.

23.Kjersti Aas, 2016,"Pair-Copula Constructions for Financial Applications: A Review", Econometrics, 4, 43,1-15. 
24.Kojadinovic, I., Yan, J.: Modeling multivariate distributions with continuous margins using the copula R package. Journal of Statistical Software 34(9), 1-20 (2010)

25.Krupskii,P., and H Joe, Factor copula models for multivariate data, Journal of Multivariate Analysis, 120, p.85-101, September, 2013.

26.Kurowicka, D., Cooke, R.: Distribution-Free Continuous Bayesian Belief Nets. In: A. Wilson, N. Limnios, S. Keller-McNulty, Y. Armojo (eds.) Modern Statistical and Mathematical Methods in Reliability, pp. 309-323 (2005)

27.Lambert, P., 2007. Archimedean copula estimation using Bayesian splines smoothing techniques. Computational Statistics \& Data Analysis 51, 6307-6320

28.Manner, H. and Reznikova, O. A Survey on Time-Varying Copulas: Specifi- cation, Simulations, and Application. Econometric Reviews, 31(6):654-687, 2012.

29.OH, D.H.; PATTON, A.J. Time-Varying Systemic Risk: Evidence from a Dynamic Copula Model of CDS Spreads. Economic Research Initiatives at Duke (ERID) Working Paper No. 167, 2013.

30.Patton, A. J. Copula-Based Models for Financial Time Series. In Mikosch, T., Kreiß, J.-P., Davis, R. A., and Andersen, T. G., editors, Handbook of Financial Time Series, pages 767-785. Springer Berlin Heidelberg, 2009a.

31. Patton, A. J. A Review of Copula Models for Economic Time Series. Journal of Multivariate Analysis, 110:4-18, September 2012.

32.Patton, A. J. Copula Methods for Forecasting Multivariate Time Series. In Elliott, G. and Timmermann, A., editors, Handbook of Economic Forecasting, volume 2 of Handbook of Economic Forecasting, pages 899 - 960. Elsevier, 2013.

33. Patton, A. J., Politis, D. N., and White, H. Correction to "Automatic BlockLength Selection for the Dependent Bootstrap" by D. Politis and H. White. Econometric Reviews, 28(4):372-375, 2009 b.

34.Peter, C.,C. Bo ,and K. Jacobs ,(2013), "Market Skewness Risk and the Cross-Section of Stock Returns", Journal of Financial Economics, 107, pp. 46-68. 
35.Qu, L., Qian, Y., Xie, H., 2009. Copula density estimation by total variation penalized likelihood. Communications in Statistics Simulation and Computation 38, 1891-1908.

36.Savu, C., and M. Trede (2010) Hierarchies of Archimedean copulas, Quantitative Finance, vol. 10, issue 3, 295-304.

37.Sklar, (1959). Fonctions de répartition à $n$ dimensions et leurs marges, Publ. Inst. Statist. Univ. Paris 8: 229-231. .

38.Stephenson, A. G. (2009), High-dimensional parametric modelling of multivariate extreme events, Australian \& New Zealand Journal of Statistics, 51(1), 77-88. 